\title{
Robust Regeneration of Adult Sensory Axons in Degenerating White Matter of the Adult Rat Spinal Cord
}

\author{
Stephen J. A. Davies, David R. Goucher, Catherine Doller, and Jerry Silver \\ Department of Neurosciences, Case Western Reserve University School of Medicine, Cleveland, Ohio 44106
}

\begin{abstract}
We have recently reported that minimally disturbed adult CNS white matter can support regeneration of adult axons by using a novel microtransplantation technique to inject minute volumes of dissociated adult rat dorsal root ganglion neurons directly into adult rat CNS pathways (Davies et al., 1997). This atraumatic injection procedure minimized scarring and allowed considerable numbers of regenerating adult axons immediate access to the adult CNS glial terrain where they rapidly extended for long distances. A critical question remained as to whether degenerating white matter at acute and chronic stages (up to 3 months) after injury could still support regeneration. To investigate this, we have microtransplanted adult sensory neurons into degenerating white matter of the adult rat spinal cord several millimeters rostral to a severe lesion of the dorsal columns. Regeneration of donor sensory axons in both directions away from the site of transplantation was robust even
\end{abstract}

Within all white matter tracts of the adult brain and spinal cord, traumatic axotomy inflicted over a wide range of severities from that of a massive contusive injury down to the smallest of microneedle punctures (Davies et al., 1996), leads inevitably to the complete failure of the severed axons to regenerate. After a substantial lesion occurs within the dorsal column sensory system of the spinal cord, for instance, the neuronal cell bodies that lie within the dorsal root ganglia survive axotomy relatively well (Vestergaard et al., 1997). However, over the following days, the cut terminal ends of the surviving axons are transformed into the so-called sterile end balls described classically by Ramon y Cajal (1928). Remarkably, these club-shaped, dystrophic endings, which are the unmistakable morphological hallmark of regeneration failure in the adult CNS, can remain in the near vicinity of a lesion without synaptic contact for many months or even years. At the center of a long-standing debate is whether regeneration failure is caused by a localized barrier presented by physical and/or molecular constraints found within scar tissue at the site of injury (Windle et al., 1952; Berry et al., 1983; Hoke and Silver, 1996; Fields et al., 1999) or to a more globally distributed inhibition effected as part of normal development by proteins associated with mature myelin (Schwab et al., 1993; McKerracher et al.,

Received Feb. 4, 1999; revised April 12, 1999; accepted April 27, 1999.

This work was supported by the National Institute of Neurological Diseases and Stroke (NS25713), the Daniel Heumann Fund, the Brumagin Memorial Fund, and the International Spinal Research Trust. We thank J. Hayes for her technical assistance and R. Miller for supplying the O4 antibody. We are very grateful to Drs. Masaru Okabe and Masahito Ikawa of the Research Institute for Microbial Diseases, Osaka University for developing and supplying the EGFP transgenic mice.

Correspondence should be addressed to Jerry Silver, Department of Neurosciences, Case Western Reserve University School of Medicine, 10900 Euclid Avenue, Cleveland, OH 44106.

Copyright (C) 1999 Society for Neuroscience $\quad 0270-6474 / 99 / 195810-13 \$ 05.00 / 0$ within white matter undergoing fulminant Wallerian degeneration despite intimate contact with myelin. Along their route, the regrowing axons extended large numbers of collaterals into the adjacent dorsal horn. However, after entering the lesion, the rapidly extending growth cones stopped and became dystrophic within high concentrations of reactive glial matrix. Our results offer compelling evidence that the major environmental impediment to regeneration in the adult CNS is the molecular barrier that forms directly at the lesion site, and that degenerating white matter beyond the glial scar has a far greater intrinsic ability to support axon regeneration than previously thought possible.

Key words: spinal cord; regeneration; inhibitory proteoglycans; transplantation; reactive astrocytes; glial scar; growth cone; myelin inhibition; extracellular matrix

1994) combined with a general downregulation of axon growth support throughout the adult CNS (Ramon y Cajal, 1928; David and Aguayo, 1981).

Contrary to these latter theories, we have recently demonstrated the rapid, long distance regeneration of sensory axons from fully adult dorsal root ganglion (DRG) neurons microtransplanted into the minimally disturbed corpus callosum and fimbria, two major white matter pathways of the adult brain (Davies et al., 1997). In the majority of cases, the microtransplantation technique (Emmett at al., 1989; Davies et al., 1993, 1994) prevented glial scarring and its associated extracellular matrix (ECM) inhibitors, thereby allowing the growth cones of regenerating adult sensory axons direct access to heavily myelinated adult CNS white matter where they grew rapidly, averaging over $1 \mathrm{~mm} /$ day. At no time, before or after microtransplantation, were the adult donor DRG neurons treated with neurotrophins, as recently stated by Cal et al. (1999) to be a necessary prerequisite to overcome axon growth inhibition effected by myelin-associated glycoprotein.

In $\sim 15 \%$ of the grafts in our previous adult DRG transplantation study (Davies et al., 1997), where damage had exceeded a critical threshold, axons failed to regenerate across the graft/host interface. Interestingly, although GFAP staining showed no evidence of a physical astroglial barrier, the point at which axons had stopped or actively turned away from the graft boundary correlated precisely with the presence of high levels of chondroitin sulfate proteoglycans (CSPGs) within host white matter extracellular matrix. Previous studies have shown that scar-associated proteoglycans are potent inhibitors of axon growth in vitro (McKeon et al., 1994). Many members of the proteoglycan family also present molecular barriers to the growth of axons during 
development of the CNS (Snow et al., 1990; Lander, 1993; Margolis and Margolis, 1993).

Thus, axon regeneration as well as its failure can occur within minimally disturbed white matter. However, what was of vital importance to learn was whether adult DRG neurons could regenerate axons in their normal pathways of the spinal cord and, more significantly, whether they could do so in a tract that had sustained a degree of trauma similar that which occurs after debilitating injuries of the spinal cord in humans. White matter distal to a large lesion undergoes many cellular and molecular changes from acute to chronic stages after trauma, including axon degeneration (Ramon y Cajal, 1928; George and Griffin, 1994) myelin degradation (Franson and Ronnevi, 1984), glial cell death (Liu et al., 1997), reactive glial responses (Berry et al., 1983; Murray et al., 1990), and glial precursor invasion (Skoff, 1975; Amat et al., 1996), as well as a cascade of inflammatory cell (Gehrmann et al., 1995; Koshinaga and Whittemore, 1995; Bruck, 1997) and cytokine responses (Giulian et al., 1994; DiProspero et al., 1997) whose effects on the ability of the damaged CNS to support axon growth are at present poorly understood.

The technical limitation of distinguishing donor neurons and their axons from host white matter dictated that our original adult microtransplantation study be conducted within adult white matter tracts of the brain in which the regenerating sensory axons would never normally reside. Preparation of adult DRG neuronal suspensions from transgenic mice that strongly express green fluorescent protein (Okabe et al., 1997) and their transplantation into normal adult rats in the present study has allowed us to characterize the regeneration of adult sensory axons within their correctly matched spinal pathways.

Because of the atraumatic nature of microtransplantation, we reasoned that adult donor neurons could be introduced several millimeters distal to a severe lesion of the dorsal columns without the further induction of scar-associated barriers. In this way the present study tested for the first time, whether adult sensory axon regeneration could still occur within white matter undergoing large scale Wallerian degeneration at both acute and chronic stages after injury.

\section{MATERIALS AND METHODS}

\section{Dissociation of adult dorsal root ganglion neurons}

Single cell suspensions of DRG were prepared from adult 2- to 3-monthold transgenic mice maintained on a C57BL/6N background and expressing the gene for enhanced green fluorescent protein $(\operatorname{TgN}(\beta$-actEGFP)01Obs to $05 \mathrm{Obs}$ ) under the control of a chicken $\beta$-actin promoter and cytomegalovirus enhancer (Okabe et al., 1997). Strongly expressing adult mice were selected with a Woods "black light". Lumbar and cervical DRGs were rapidly dissected, incubated in dispase $(2.5 \mathrm{U} / \mathrm{ml}$; Boehringer Mannheim, Indianapolis, IN) and collagenase type 2 (200 $\mathrm{U} / \mathrm{ml}$; Worthington, Freehold, NJ) for $100 \mathrm{~min}$ at room temperature. Enzyme was removed, and DRGs were triturated in $1 \mathrm{ml}$ calcium and magnesium-free HBSS media with $5 \mu \mathrm{g} / \mathrm{ml}$ DNase (Sigma, St. Louis, MO) and then spun at low $g$ (2000 rpm) for $90 \mathrm{sec}$ in a 54156 Eppendorf centrifuge. Supernatant containing the bulk of peripheral glia and debris was removed, and the pellet was resuspended in $1 \mathrm{ml}$ of calcium and magnesium-free HBSS media. The suspension was centrifuged again (as above), supernatant was removed, and the final neuron-enriched pellet was resuspended in 50-100 $\mu \mathrm{l}$ of L15 media with $5 \mu \mathrm{g} / \mathrm{ml}$ DNase for an average neuronal density of 680 neurons per microliter. No growthenhancing supplements such as neurotrophins were added to the adult DRG suspensions, which were stored on ice for no longer than $5 \mathrm{hr}$ before microtransplantation. Small aliquots of cells from two representative adult DRG suspensions were plated onto a laminin substrate $(25$ $\mu \mathrm{g} / \mathrm{ml}$ ) in DMEM F-12 media for overnight tissue culture and immunohistochemical characterization of cell types (see below). All media were supplied by Life Technologies (Gaithersburg, MD).
Table 1. Numbers of cases at each time point for experimental sets 1 , 2 , and 3

\begin{tabular}{|c|c|c|c|c|c|c|}
\hline \multirow[b]{2}{*}{$\begin{array}{l}\text { Survival } \\
\text { days }\end{array}$} & \multicolumn{3}{|l|}{ Exp 1} & \multicolumn{2}{|l|}{ Exp 2} & \multirow{2}{*}{$\begin{array}{l}\text { Exp } 3 \\
\text { Chronic }\end{array}$} \\
\hline & $\begin{array}{l}\text { No } \\
\text { lesion }\end{array}$ & Acute & $\begin{array}{l}\text { Sub- } \\
\text { chronic }\end{array}$ & $\begin{array}{l}\text { No } \\
\text { lesion }\end{array}$ & Acute & \\
\hline 3 & & $2(\mathrm{EM})$ & $1(\mathrm{EM})$ & & & \\
\hline 4 & 4 & 2 & 3 & & & \\
\hline 6 & & & 2 & & & \\
\hline 8 & 4 & 2 & 2 & 2 & 4 & 4 \\
\hline 10 & & & 2 & 2 & 3 & \\
\hline 14 and 21 & 3 & 2 & & & & \\
\hline
\end{tabular}

Total number of unlesioned cases, 15 ; total number of acute lesioned cases, 15 ; total number of subchronic lesioned cases, 10; total number of chronic lesioned cases, 4.

\section{Surgery}

For all experimental sets 1-3, adult Sprague Dawley female rats (200225 gm, Charles River Laboratories, Wilmington, MA) were anesthetized with intramuscular ketamine $(100 \mathrm{mg} / \mathrm{kg})$ and xylazine $(2.4 \mathrm{mg} /$ $\mathrm{kg}$ ). We slowly injected $(5 \mathrm{~min}) 0.75 \mu \mathrm{l}$ volumes of cell suspension with a Picospritzer (General Valve, Fairfield, NJ) through a glass micropipette with a bevelled tip and outer and inner diameters of 90 and $70 \mu \mathrm{m}$, respectively. Each micropipette was graduated at 0.5 and $1 \mathrm{~mm}$ from its tip to help ensure that transplants were injected at a depth of no greater than $0.5 \mathrm{~mm}$ from the pial surface into right side cervical dorsal column white matter. No immunosuppressant treatment was used.

Experimental set 1. All adult GFP DRG microtransplants in experimental set $1(n=29)$ were injected into the right side dorsal columns at the intervertebral junction of vertebrae $\mathrm{C} 1$ and $\mathrm{C} 2$. For acute $(n=8)$ and subchronically lesioned ( 2 weeks before graft injection, $n=10$ ) cases, the right side dorsal columns were unilaterally transected to a minimum depth of $1 \mathrm{~mm}$ between cervical vertebrae 4 and 5, using a 30 gauge needle as a blade.

Experimental sets 2 and 3. All adult GFP DRG microtransplants in experimental set $2(n=11)$ and set $3(n=4)$ were injected into the right side dorsal columns at the level of the medulla just rostral to the $\mathrm{C} 1$ vertebra. Acute set 2 cases $(n=7)$ immediately received lesions of the right side dorsal columns at $\mathrm{C} 1 / \mathrm{C} 2$ using a 30 gauge needle, as described above, whereas we waited a period of 3 months before transplantation into chronic set 3 animals after an identical lesion.

\section{Histology}

Immunohistochemistry. After postoperative periods of 4, 6, 8, 10, 14, and $21 \mathrm{~d}$ for animals in experimental set 1,8 and $10 \mathrm{~d}$ for experimental set 2 , and $8 \mathrm{~d}$ for experimental set 3 (Table 1), animals were transcardially perfused with $0.1 \mathrm{M}$ phosphate buffer (PB) and $4 \%$ paraformaldehyde before processing for immunohistochemical analysis. Dissected spinal cords were post-fixed in $4 \%$ paraformaldehyde with $60 \mu \mathrm{m}$ vibratome sections cut in the sagittal plane, parallel to the alignment of the central canal. One 8 d subchronic survival case from experimental set 1 , had sections cut in the coronal plane. Spinal tissue containing lesion sites in experimental set 1 was processed for semithin sectioning (see below). Sections for immunohistochemistry and $4 \%$ paraformaldehyde fixed tissue culture coverslips were washed in PBS, blocked with $4 \%$ goat serum with $0.1 \%$ Triton X-100 in PBS, and incubated overnight with appropriate primary antibodies in blocking solution followed by secondary and tertiary steps for single, double, and triple staining by standard immunocytochemical methods. Polyclonal and monoclonal antibodies for GFP (Clontech, Cambridge, UK; 1:500, 1:200, respectively) and polyclonal anti-CGRP (Peninsula Laboratories, Belmont, CA; 1:350) were used to identify donor neurons. Primary antibodies for the following antigens were also used: GFAP, astrocytes (Sigma; 1:400), vimentin, astrocytes (Chemicon, Temecula, CA; 1:200), p75 peripheral glia tissue culture (Boehringer Mannheim; 1:100), CS56, chondroitin 6 and 4 sulfate proteoglycans (Sigma; 1:100), and ED1 (Chemicon; 1:200). Fluorochromes used to visualize primary antibody labeling included Oregon Green, Texas Red X, and Cy5. Stained sections and tissue culture coverslips were examined using a Zeiss laser-scanning confocal microscope and a Leitz Orthoplan 2 fluorescence light microscope.

Electron microscopy. One acute and one subchronic animal in experimental set 1 were killed at $3 \mathrm{~d}$ post transplantation and transcardially 
perfused with $4 \%$ paraformaldehyde and $2 \%$ glutaraldehyde in $0.1 \mathrm{M} \mathrm{PB}$ for electron microscopy of degenerating white matter. Tissue from these animals and lesion sites from other set 1 animals were processed using standard procedures with $1 \mu \mathrm{m}$ semithin sections for light microscopy counterstained with toluidine blue, and ultrathin sections were viewed with a JEOL 1000 electron microscope. One acute set 1 animal was transcardially perfused at $3 \mathrm{~d}$ survival with $4 \%$ paraformaldehyde fix, and HRP immunohistochemistry was conducted for GFP without Triton $\mathrm{X}-100$ treatment on $60 \mu \mathrm{m}$ sagittally orientated, free-floating vibratome sections. Sections were then osmicatted with $1 \%$ osmium tetroxide in 0.1 M sodium cacodylate buffer for $30 \mathrm{~min}$ before being processed with standard dehydration and flat-embedding resin infiltration protocols. Ultrathin sections were cut and viewed with or without a light uranyl acetate and lead citrate counterstain on a JEOL 1000 electron microscope. The extent of sparing of axons within the most medial portions of the right side dorsal columns was assessed in an animal that had sustained a typical lesion. This was accomplished with the use of a Numonics electronic graphic calculator that measured the areas of lesioned versus spared white matter in selected $1 \mu \mathrm{m}$ coronal sections through the lesion.

\section{Oligodendrocyte/DRG cocultures}

Cocultures of adult EGFP mouse DRG neurons and mature rat O4+ oligodendrocytes were established to verify that neither the suspension preparation technique or the mouse to rat species mismatch had altered the sensitivity of the EGFP DRG neurons to in vitro myelin-associated inhibition of neurite growth. Purified oligodendrocyte cultures were established from mixed glial cultures of neonatal rat cortices, by selective panning using $\mathrm{O} 4$ antibody (generously supplied by R. H. Miller). The $95 \%$ pure oligodendrocyte cell suspension was placed in N2 DMEM media containing $1 \% \mathrm{FBS}, 50 \%$ glial conditioned media, and $5 \mathrm{ng} / \mathrm{ml}$ PDGF, plated at $1 \times 10^{6}$ cells per laminin-coated $(25 \mu \mathrm{g} / \mathrm{ml}) 12 \mathrm{~mm}$ coverslip and cultured for $12 \mathrm{~d}$ to ensure differentiation and maturation. Dissociated adult GFP mouse DRGs, $\left(1 \times 10^{4}\right.$ cells per coverslip $)$ taken from suspensions used for injection in vivo, were added to the oligodendrocyte cultures and allowed to interact for $24 \mathrm{hr}$. Cultures were fixed in $4 \%$ paraformaldehyde and stained with antibodies against $\mathrm{O} 4$ (supernatant 1:1) and GFP (1:500). These cultures were compared with control DRG cultures on laminin $(25 \mu \mathrm{g} / \mathrm{ml})$ only that were immunostained for GFP (1:500) for neurons and p75 (1:100) for satellite glia.

All procedures were performed under guidelines of National Institutes of Health and approved by the Institutional Animal Care and Utilization Committee.

\section{RESULTS}

\section{Transplant morphology and cell types}

All donor neuron cell bodies and their processes in all grafts studied up to the $10 \mathrm{~d}$ survival time were intensely immunoreactive for GFP and had not migrated away from the original site of implantation. Use of the low $g$ purification method during suspension preparation ensured that grafts contained only small numbers of peripheral glia (i.e., $<20 \%$ of total cell numbers), most of which remained within the vicinity of the transplants (see Davies et al., 1997). The majority of neurons within all microtransplants injected at spinal cord levels $\mathrm{C} 1 / \mathrm{C} 2$ and caudal medulla were enclosed within the white matter of the right cuneate fasciculus with the transplant "neuropil" spanning the host tract dorsoventrally from the pial surface to the medial edge of the gray matter of layer 4 of the dorsal horn, a distance of $\sim 750 \mu \mathrm{m}$. Most grafts also had small numbers of donor neurons at their medial borders that were within the white matter of the gracile tract. Double immunofluorescence staining for GFP and CGRP confirmed that $\sim 30 \%$ of donor neurons (mainly small diameter) within transplants were CGRP + , with large-diameter $(>40 \mu \mathrm{m}$; see Fig. 2c) CGRP neurons accounting for $\sim 20 \%$ of total GFP+ neurons. Characterization of aliquots of cells taken from suspensions used for transplantation revealed similar percentages of large-diameter and CGRP+ neurons and glia after overnight tissue culture on a laminin substrate in DMEM F-12 media. Identically prepared adult GFP + mouse DRG neurons extended relatively short neurites $(<100 \mu \mathrm{m})$ when cocultured for $24 \mathrm{hr}$ on mature rat $\mathrm{O} 4+$ oligodendrocytes compared with their growth on a laminin substrate alone (data not shown). All grafts were injected using suspensions that had been kept on ice at $4^{\circ} \mathrm{C}$ in L15-defined minimal media (no added neurotrophins) for no longer than $5 \mathrm{hr}$ after DRG dissociation.

The five transplants in experimental set 1 grafted to unlesioned and acutely lesioned spinal cords with survival times of $14(n=3)$ and $21 \mathrm{~d}(n=2)$ (Table 1$)$ all exhibited signs of immune rejection with reduced numbers of GFP + neuronal cell bodies and axons. ED1 immunostaining of these animals revealed large numbers of activated macrophages at the site of transplantation and perivascular "cuffing" in adjacent white matter. We, therefore, confined our analyses to microtransplants with survival times of between 3 and $10 \mathrm{~d}$. Because of improvements in tissue dissociation and grafting technique, there were no cases of regeneration failure directly at the graft boundaries. Panels in Figures 2-4, 6, and 7 are orientated with rostral structures at the top and dorsal structures to the right, unless otherwise stated.

\section{Lesion and distal tract morphology: experimental sets 1 and 2}

Semithin sections cut in cross section through the spinal cords of animals that had received either unilateral lesions of the right side dorsal columns at levels $\mathrm{C} 1 / \mathrm{C} 2$ or $\mathrm{C} 4 / \mathrm{C} 5$ showed a near complete transection of the dorsal columns with sparing of only $5-10 \%$ (assessed with the use of a Numonics electronic graphic calculator) of the most medial fibers (Figs. 1, 2e). Electron microscopy of the dorsal column white matter at 15 and $2 \mathrm{~mm}$ rostral to a C4/C5 lesion at the 2 week chronic time point showed large numbers of degenerating host axons and their disrupted myelin in the cuneate and gracile fasciculi. Degenerating axons exhibited the characteristic granular disintegration of their cytoskeletons with their surrounding myelin undergoing ovoid formation, as previously described by George and Griffin (1994). Host white matter astrocytes distal to the lesions and especially those close to the pial surface, showed a marked increase in GFAP immunostaining at all experimental time points (Figs. $2 d$, $3 a, b$; see $6 a$ ). Although hypertrophic in appearance, the host white astrocytes within distal tract undergoing Wallerian degeneration had maintained their normal alignment of longitudinal and radial processes (Fig. 4a).

\section{Experiment 1: axon regeneration from $C 1 / C 2$ transplants}

Surprisingly, there was little appreciable difference in the overall maximum distance, axon morphology, or patterning of axonal outgrowth from the adult DRG microtransplants grafted to unlesioned, acutely lesioned, or subchronically ( 2 weeks) lesioned dorsal column spinal cord white matter. Therefore, the following characterization of the growth of donor GFP axons in host white and gray matter for survival times ranging from 4 to $10 \mathrm{~d}$ is generally applicable to all transplants in experimental set 1 .

\section{Distances and pattern of axonal outgrowth}

At $4 \mathrm{~d}$ after transplantation many hundreds of GFP-labeled axons had exited the grafts in both rostral and caudal directions, with some having reached a maximum distance of $\sim 4.6 \mathrm{~mm}$ within the white matter of the cuneate and gracile spinal cord pathways. By $8 \mathrm{~d}$ survival (Fig. 2a,b), axons had reached maximum distances of $\sim 8-9 \mathrm{~mm}$ in host white matter (Table 2) and $11 \mathrm{~mm}$ by $10 \mathrm{~d}$ survival. Axon outgrowth was staggered in that growth cones were observed at a variety of short (1-3 mm) to long $(6-11 \mathrm{~mm})$ distances from graft boundaries with the majority at middle 


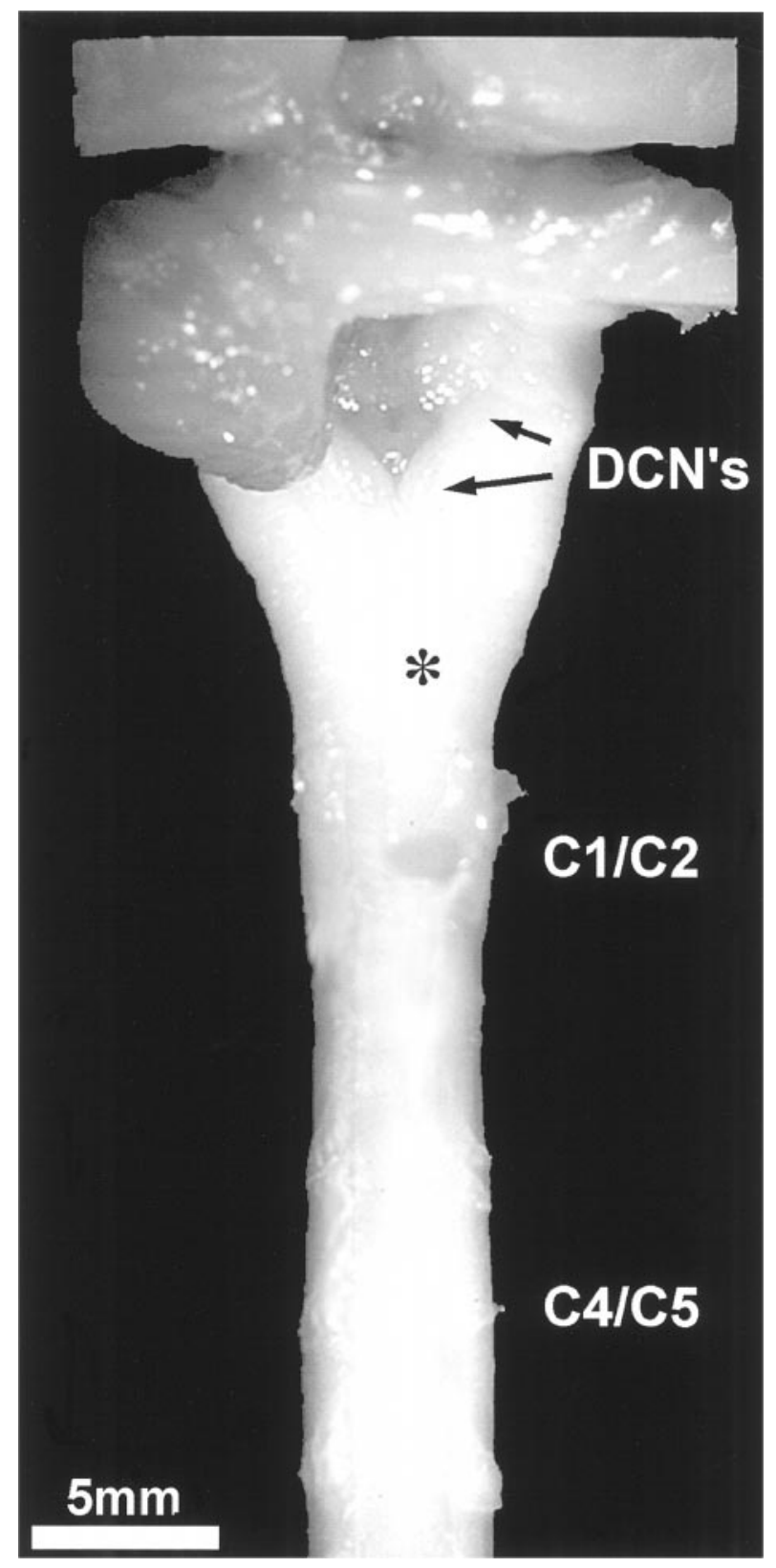

Figure 1. Sites of transplantation and lesions. A photomicrograph of the hindbrain and cervical spinal cord of an adult rat that shows the relative positions of transplants and lesions in experimental sets 1-3 within the right side of the dorsal column sensory pathways. For experimental set 1 , transplants were injected at the cervical level of $\mathrm{C} 1 / \mathrm{C} 2$, and lesions were placed $\sim 14 \mathrm{~mm}$ caudally at the $\mathrm{C} 4 / \mathrm{C} 5$ intervertebral junction. For experimental sets 2 and 3, transplants were injected into dorsal column white matter at the level of the medulla (asterisk), and lesions were placed 4-5 $\mathrm{mm}$ caudally at $\mathrm{C} 1 / \mathrm{C} 2$ (visible in this particular animal). A portion of the cerebellum has been removed during dissection to expose the dorsal column nuclei (DCNs, arrows).

distances for each time point. Comparison of the maximum distances of axon growth at $4 \mathrm{~d}$ survival of unlesioned versus acute and chronic lesioned cases showed a small trend toward $<1$ $\mathrm{mm}$ lag for the acute and subchronic animals. However, this relatively minor deficit had been made up by the $8 \mathrm{~d}$ time point (Table 2). Counts of axonal profiles at a distance of $2 \mathrm{~mm}$ from a representative graft of $8 \mathrm{~d}$ survival within subchronically lesioned white matter in the rostral and caudal directions gave totals of 433 and 440, respectively. With transplants having grown a total of $>800$ axonal processes by $8 \mathrm{~d}$ from an average count of $\sim 510$ neurons/750 $\mathrm{nl}$ injection, it is likely that donor neurons had sent out more than one process that had travelled in opposite directions from the site of transplantation. However, it was very difficult to determine the relative proportions of neurons that were unipolar or bipolar. A few donor axons were observed to have looped back on themselves, however it seems unlikely that they accounted for the discrepancy between neuron and axon numbers.

Within host white matter, the highly varicose regenerating axons grew with a remarkably straight trajectory, extending for equally long distances either singly or in fascicles in all subportions of host white matter. Figures $2 a-d, 3, a$ and $b$, and $6 a$, show large numbers of axons (up to 131 caudally, in one $60 \mu \mathrm{m}$ section alone; Fig. 2c) that have grown equally well within subchronically lesioned dorsal column white matter adjacent and parallel to the host gray-white interface as well as several hundreds of micrometers away at the boundary of the cuneate and gracile tracts, the pial surface, and all points in between. Indeed, the dorsoventral/ lateral-medial positioning of the donor neuronal cell bodies within host white matter appeared to be the sole determinant of where axons grew in relation to the pial surface and the dorsal horn gray matter. Small numbers of GFP donor axons at the pial surface of unlesioned and lesioned dorsal columns at all time points were observed to have crossed the dorsal root entry zones, rostral and caudal to transplants, out into the Schwann cell territory of the dorsal root (data not shown). A systematic analysis of the extent of this growth into the peripheral nervous system was not made.

\section{Growth cone morphology and axon relationship to host astrocytes and myelin}

At the rostral and caudal white matter interfaces of all grafts studied in experimental set 1, numerous hypertrophic GFAP+ host astrocytic processes had invaded transplant neuropil with donor axons exiting in strict alignment with the glia, as previously described for intracallosal and intrafimbrial grafts (Davies et al., 1997). The majority of regenerating GFP+ adult sensory axons within unlesioned and degenerating host white matter alike, exhibited "streamlined" growth cones, typically having a single leading filopodia (Fig. 4c). Growth cones and their trailing primary axon shaft many millimeters from the graft host interface were also closely aligned with the longitudinal processes of host white matter astrocytes (Fig. $4 a$ ), with axons having elongated equally long distances within regions of relatively higher or lower GFAP immunoreactivity. Growth cones with a more expanded morphology and numerous filopodia were occasionally observed within white matter adjacent to the gray-white interface of the dorsal horn in lesioned (Fig. 4b) and unlesioned animals. Immunoelectron microscopy of GFP-labeled donor axons within acutely lesioned host white matter at $3 \mathrm{~d}$ after transplantation showed that the profiles of rapidly regenerating axons had typically grown in intimate contact with both degenerating myelin and astrocytes (Fig. 5a,b).

\section{Terminal field invasion}

At all experimental time points up to $10 \mathrm{~d}$ after transplantation and at all distances from grafts (set 1), similarly large numbers of donor GFP + primary axons within unlesioned, acutely lesioned, and subchronically lesioned host white matter had grown collaterals that had invaded and repeatedly branched within layers 1 

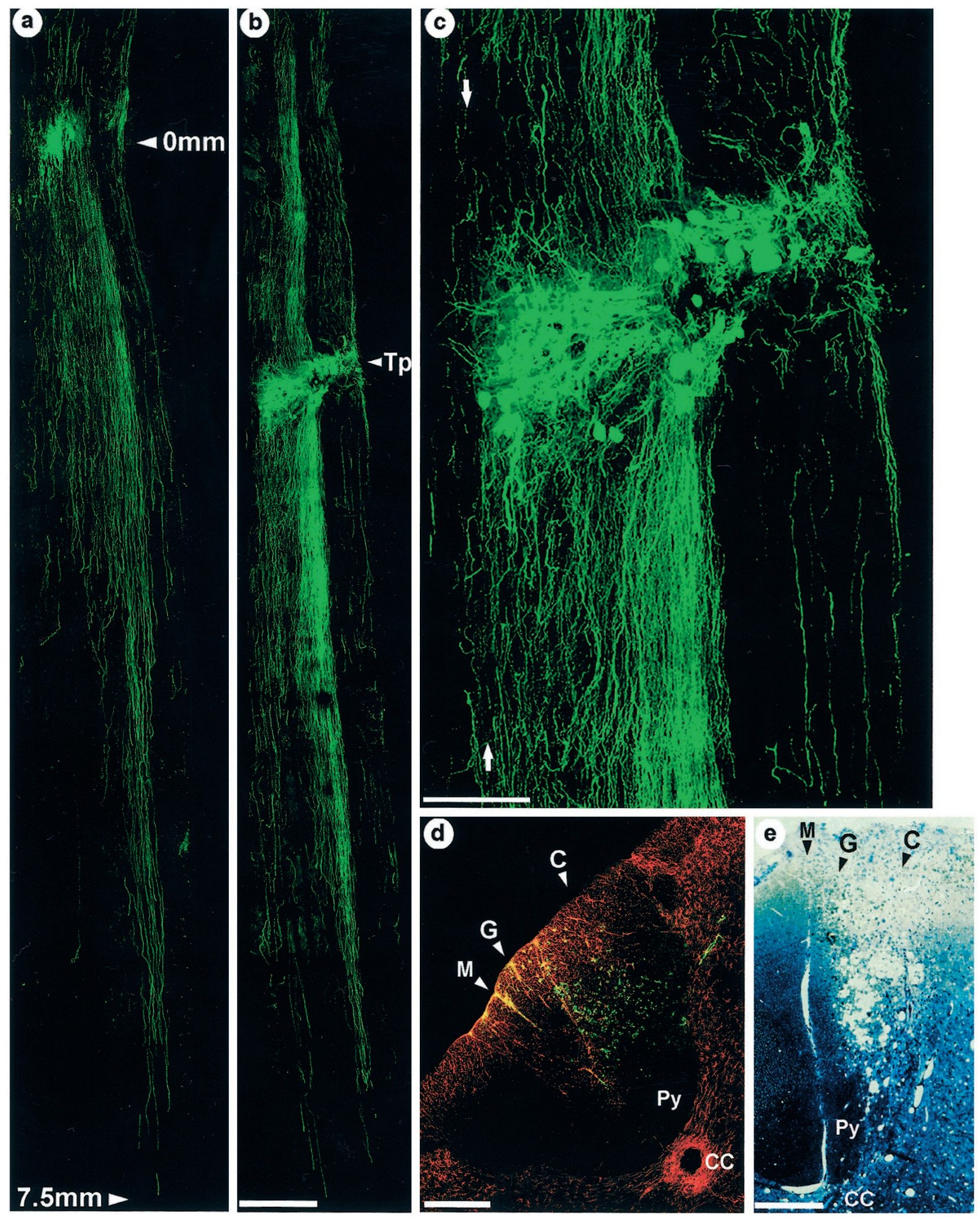

Figure 2. Long distance adult axon regeneration in degenerating spinal cord white matter. $a$, A confocal montage of scans from a single sagittally orientated $60 \mu \mathrm{m}$ section showing the long distance growth $(7.5 \mathrm{~mm}$ shown in this section) of numerous GFP-immunolabeled adult sensory axons that have extended caudally from a $\mathrm{C} 1 / \mathrm{C} 2$ set 1 transplant $($ at $0 \mathrm{~mm}$ ) within acutely lesioned dorsal column white matter at $8 \mathrm{~d}$ survival. $b$, A similarly constructed confocal montage showing the robust bidirectional regeneration of GFP+ donor axons from a set 1 transplant (Tp, arrowhead) injected into 2 week subchronically degenerated dorsal column white matter at $8 \mathrm{~d}$ survival after transplantation. Scale bar, $500 \mu \mathrm{m}$. $c$, A high-power confocal image of the transplant in $b$ containing individual large and small neuronal cell bodies with their axons extending out into host white matter. Arrows indicate position of dorsal horn gray-cuneate white matter boundary. Scale bar, $200 \mu \mathrm{m}$. $d$, A double-channel confocal image of a coronally orientated $60 \mu \mathrm{m}$ section immunostained for GFP ( green channel) and GFAP (red channel) $2 \mathrm{~mm}$ rostral to an $8 \mathrm{~d}$ survival transplant at $\mathrm{C} 1 / \mathrm{C} 2$. Numerous end on profiles of GFP+ regenerating axons can be seen throughout subchronically degenerating white matter of the cuneate $(C$, arrowhead $)$ and gracile $(G$, arrowhead $)$ fasciculi. $M$ (arrowhead), Midline; Py, pyramidal tract; $C C$, central canal. Scale bar, $250 \mu \mathrm{m}$. $e$, A $1 \mu \mathrm{m}$ semithin section cut in the coronal plane counterstained with toluidine blue of a representative C4/C5 lesion site. Note the complete transection of the cuneate fasciculus $(C$, arrowhead) and sparing of only a small portion of the most medial axons of the gracile tract $(G$, arrowhead). Scale bar, $200 \mu \mathrm{m}$. 

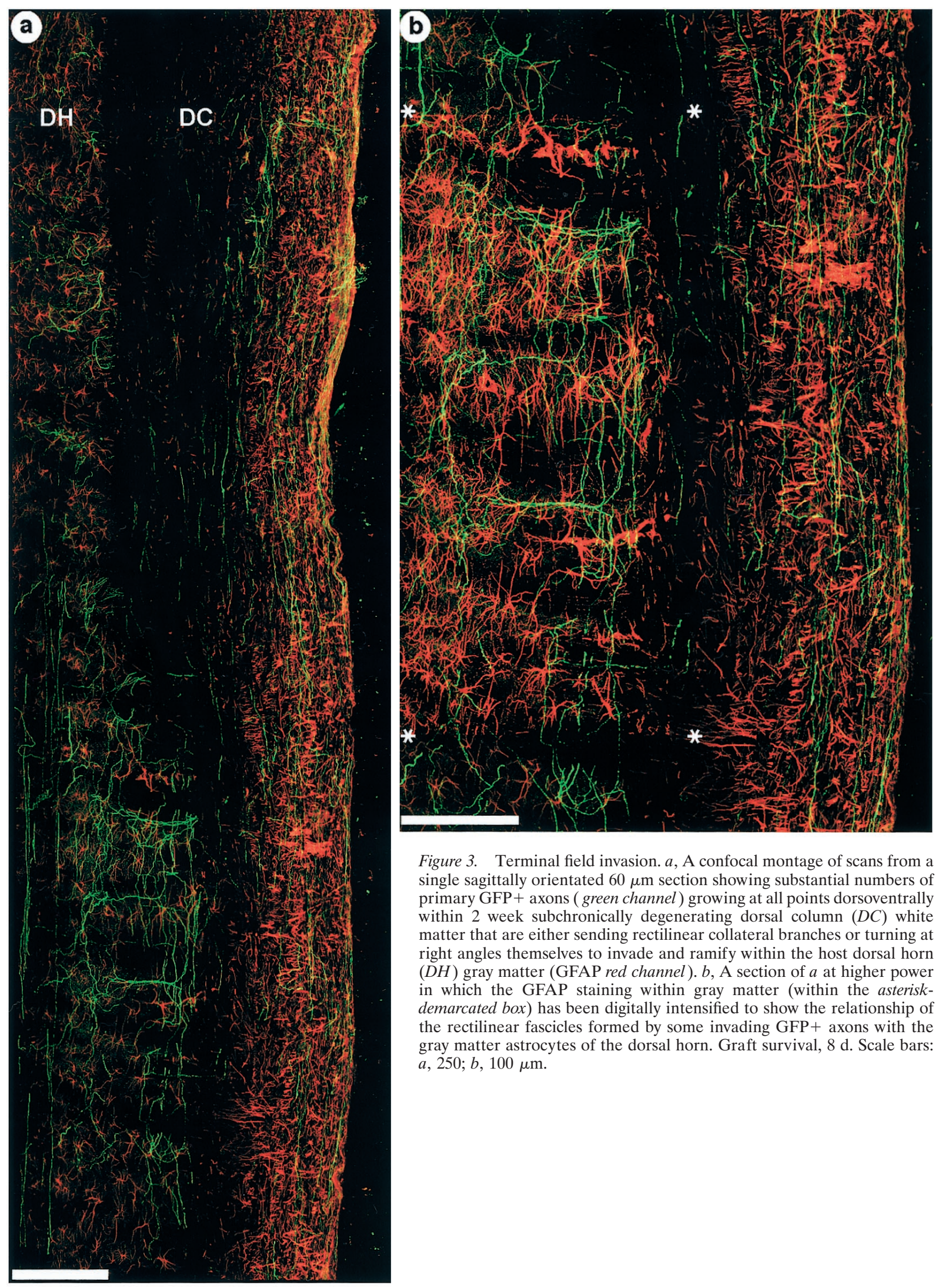

Figure 3. Terminal field invasion. $a$, A confocal montage of scans from a single sagittally orientated $60 \mu \mathrm{m}$ section showing substantial numbers of primary GFP + axons ( green channel) growing at all points dorsoventrally within 2 week subchronically degenerating dorsal column $(D C)$ white matter that are either sending rectilinear collateral branches or turning at right angles themselves to invade and ramify within the host dorsal horn $(D H)$ gray matter (GFAP red channel). $b$, A section of $a$ at higher power in which the GFAP staining within gray matter (within the asteriskdemarcated box) has been digitally intensified to show the relationship of the rectilinear fascicles formed by some invading GFP+ axons with the gray matter astrocytes of the dorsal horn. Graft survival, $8 \mathrm{~d}$. Scale bars: $a, 250 ; b, 100 \mu \mathrm{m}$ 

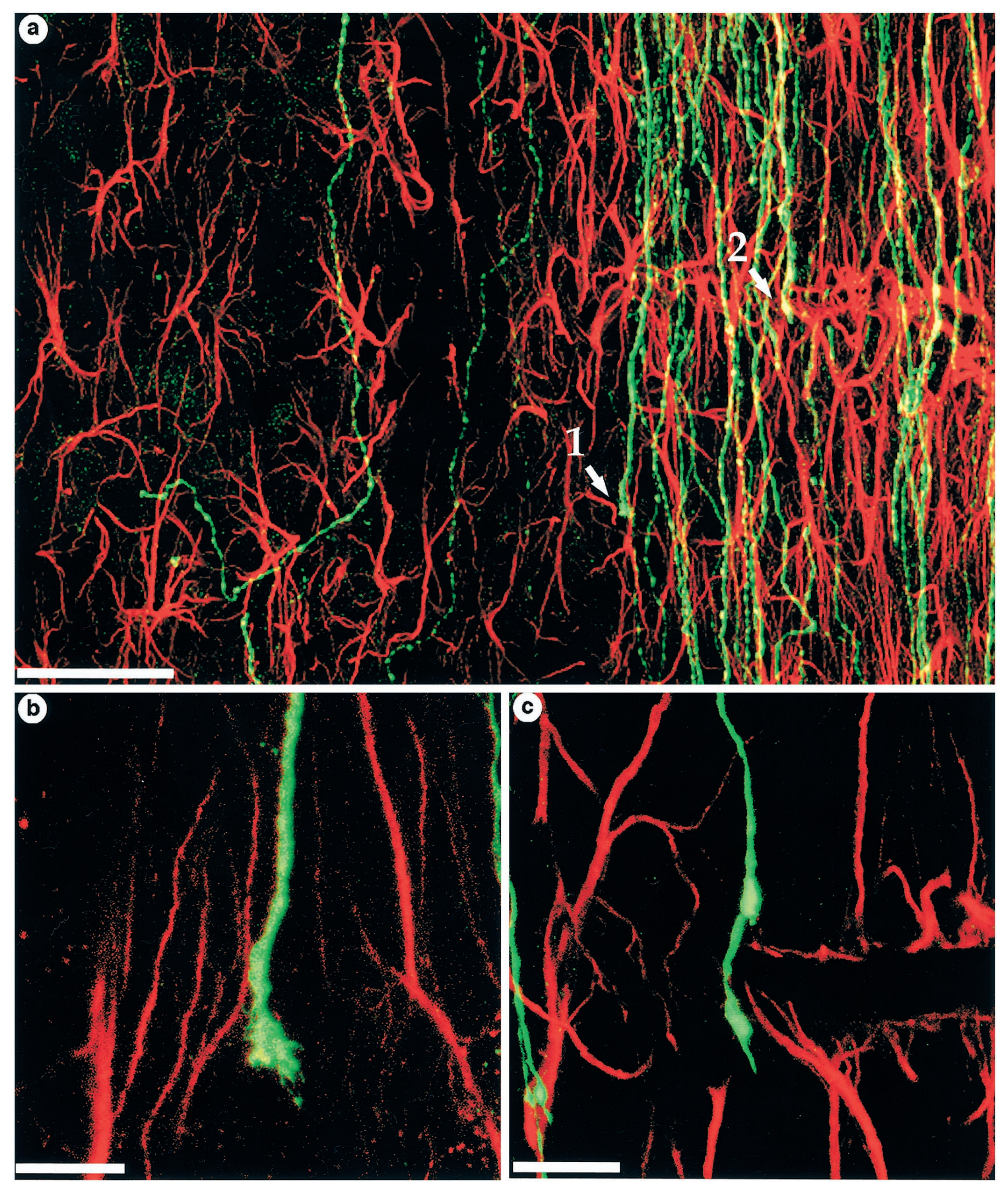

Figure 4. Morphology of growth cones and relationship to host astrocytes. $a$, A confocal scan at a distance of 4 mm caudal to an $8 \mathrm{~d}$ survival set 1 transplant showing GFP+ (green channel) axons growing in parallel to the longitudinal processes of host astrocytes $(G F A P$, red channel) within acutely degenerating white matter at its interface with host dorsal horn gray matter that contains typically stellate astrocytes. Arrow 1 indicates an example of a growth cone at the gray-white interface (higher power panel $b$ ) displaying several filopodia on a more expanded tip, possibly indicating that it is in the process of making a decision to invade gray matter. Arrow 2 points to an example of a "streamlined" growth cone with a single filopodium, a morphology typically displayed by regenerating axons within white matter. $c$ shows this growth cone at higher power as it skirts a blood vessel. Scale bars: $a, 50 \mu \mathrm{m} ; b, c, 10 \mu \mathrm{m}$ 


\begin{tabular}{|c|c|c|c|}
\hline Time point and status & $\begin{array}{l}\text { Animal } \\
\text { ID \# }\end{array}$ & $\begin{array}{l}\text { Rostral } \\
\text { distance } \\
(\mathrm{mm})\end{array}$ & $\begin{array}{l}\text { Caudal } \\
\text { distance } \\
(\mathrm{mm})\end{array}$ \\
\hline \multirow[t]{4}{*}{$4 \mathrm{~d}$ unlesioned } & $\mathrm{R} 220$ & 3.7 & 4.3 \\
\hline & R221 & 3.8 & 4.6 \\
\hline & $\mathrm{R} 227$ & 3.5 & 3.9 \\
\hline & R228 & 3.3 & 3.7 \\
\hline \multirow[t]{2}{*}{$4 \mathrm{~d}$ acute } & $\mathrm{R} 237$ & 2.9 & 3.3 \\
\hline & $\mathrm{R} 243$ & 2.8 & 3.1 \\
\hline \multirow[t]{3}{*}{4 d subchronic } & R246 & 3.0 & 3.7 \\
\hline & $\mathrm{R} 247$ & 2.9 & 3.2 \\
\hline & $\mathrm{R} 252$ & 2.7 & 3.5 \\
\hline \multirow[t]{4}{*}{$8 \mathrm{~d}$ unlesioned } & R222 & 7.1 & 9.1 \\
\hline & $\mathrm{R} 223$ & 7.9 & 8.5 \\
\hline & $\mathrm{R} 226$ & 6.8 & 8.1 \\
\hline & $\mathrm{R} 232$ & 6.6 & 8.2 \\
\hline \multirow[t]{2}{*}{$8 \mathrm{~d}$ acute } & R239 & 6.7 & 7.5 \\
\hline & $\mathrm{R} 240$ & 7.8 & 8.1 \\
\hline \multirow[t]{2}{*}{$8 \mathrm{~d}$ subchronic } & $\mathrm{R} 248$ & 6.8 & 8.8 \\
\hline & R249 & 7.1 & 8.3 \\
\hline
\end{tabular}

through 5 of host spinal cord gray matter (Fig. 3a,b). However, significant numbers of primary axons were also observed to have turned ventrally or laterally out of the dorsal column white matter and elaborated terminal field-like plexi (Fig. 3a,b). At longer survival times, the terminal branching of these primary axons and collaterals was noticeably more complex, suggesting attempted terminal field innervation. In a small number of grafts where the most ventrolaterally located donor neurons resided within host gray matter, process outgrowth was comparatively short compared with that in white matter, with many axons immediately exhibiting terminal branching. Axons were observed within white matter at the entrances to the gracile and cuneate nuclei, distances of $\sim 7$ and $8 \mathrm{~mm}$, respectively, but had not ramified within these terminal fields by $10 \mathrm{~d}$ after transplantation (the longest time point fully characterized) in all experimental animals.

\section{Experiment 2: axon regeneration from medulla transplants}

In the case of acute and 2 week subchronically lesioned animals in experimental set 1 , caudally projecting axons failed to traverse the $\sim 14 \mathrm{~mm}$ distance to interact with the lesion site at $\mathrm{C} 4 / \mathrm{C} 5$ before succumbing to immune rejection. Therefore, to allow caudally regenerating donor axons the opportunity of interacting with the forming glial scar, the experimental unilateral lesions in experimental set 2 were made at $\mathrm{C} 1 / \mathrm{C} 2,4-5 \mathrm{~mm}$ caudal to transplants placed within the acutely degenerating white matter of the dorsal columns at medullary levels (Fig. 1). Survival times of 8 and $10 \mathrm{~d}$ were studied for EGFP DRG microtransplants grafted at the level of the medulla of control unlesioned and $\mathrm{C} 1 / \mathrm{C} 2$ acutely lesioned dorsal column white matter. In a similar manner to grafts studied in experimental set 1 , axonal outgrowth from all transplants in experimental set 2 was bidirectional, with substantial numbers of axons from transplants injected into unlesioned dorsal column white matter, growing beyond $6 \mathrm{~mm}$ caudally and smaller numbers reaching maximum caudal distances of $9 \mathrm{~mm}$ by $8 \mathrm{~d}$ and $10.5 \mathrm{~mm}$ by $10 \mathrm{~d}$.

In the case of $8 \mathrm{~d}$ and $10 \mathrm{~d}$ survival animals that had also received lesions to $\mathrm{C} 1 / \mathrm{C} 2$, large numbers of $\mathrm{GFP}+$ axons could be seen to have not only regenerated $4-5 \mathrm{~mm}$ caudally within acutely degenerating host white matter but penetrated several tens to hundreds of micrometers into the highly reactive lesion site itself (Fig. $6 a-d)$. Streamlined growth cones were observed within degenerating white matter at just a few tens of micrometers outside the lesion site and also after entering the CSPGcontaining reactive matrix of the lesion itself. Triple channel confocal microscopy of $60 \mu \mathrm{m}$ sections stained for GFP, GFAP, or vimentin (data not shown) and CSPG showed that GFP+ axons had grown inwards from the edge of the lesions up a gradient of increasingly CSPG-rich ECM containing disorganized, reactive astrocytes (Fig. $6 c, d$ ). Axons generally became more tortuous and branched as they entered more deeply into the lesion, eventually stopping at a variety of distances from the lesion periphery to near the lesion center or slightly beyond, at which points they assumed the morphology of the classically described dystrophic sterile endings that typify regeneration failure (Fig. 6e). The areas within each lesion where regenerating axons had stopped and formed dystrophic endings contained the highest concentrations of CSPGs, with sterile endings having formed within the territories of GFAP+ astrocytes (Fig. 6e) and also within adjacent areas of vimentin + astrocytes that had assumed a bipolar migratory morphology (data not shown). No axons were seen to have grown completely through any lesions studied at the 8 and $10 \mathrm{~d}$ survival times. Only 2 of the $8 \mathrm{~d}$ cases showed one axon each that had grown medially to circumvent forming scar tissue and enter the more caudal host white matter beyond.

\section{Experiment 3: regeneration of axons within chronically (3 months) degenerating white matter}

In a limited study ( $n=4$ animals), lesions were made identically to those in experimental set 2 , however, in these animals a full 3 months was allowed to elapse between the time of initial injury and grafting of donor neurons into the degenerating dorsal columns at the level of the medulla. A survival time of $8 \mathrm{~d}$ after transplantation was used for all animals in this set. Surprisingly, even at this clearly chronic time point after injury, axon regeneration from the grafts within degenerating white matter was robust. The maximum extent of axon regrowth in both rostral and caudal directions was comparable to that observed for the grafts having $8 \mathrm{~d}$ survival in experimental set 2 . Numerous axons had traversed 4-5 mm caudally from transplants only to stop and display dystrophic endings after entering the environment of the mature scar (Fig. 7a,b).

In all four cases in experimental set 3, fluorescence immunostaining for GFAP revealed that the density and disorganization of GFAP-immunoreactive processes had greatly increased in the mature scar in the rostral and caudal directions away from the lesion center compared with acute or subchronic time points. This dense meshwork of astrocytic processes had spread from the lesion site up to $1 \mathrm{~mm}$ in the caudal (proximal) white matter and from 1 to $3 \mathrm{~mm}$ in the rostral (distal) degenerating white matter, especially nearer the pial surface and in more lateral sections away from the spinal cord midline. Notably, the central area of the lesion site had a markedly lower density of GFAP + processes that no EGFP-labeled axons had penetrated (Fig. 7a,b). Immunoreactivity for CSPGs, although still present, had become more tightly associated with the membranes of astrocytes and had also spread outward from the lesion center in a pattern matching the increased astrocytic reactivity and disorganization of astrocytic processes (Fig. 7b). Triple fluorescence immunostaining for GFP, 
Figure 5. Relationship of growing axons to white matter myelin and astrocytes. $a, b$, Electron microscope images of GFP-immunolabeled regenerating adult DRG axons in intimate contact (arrowheads) with degenerating myelin membranes within acutely lesioned dorsal column white matter. Three day survival after transplantation and $1.5 \mathrm{~mm}$ distance from the graft ensures that these profiles are near the growing tips of the axons. However, the dense HRP labeling prevented the ability to distinguish bona fide growth cones from axonal varicosities. Note that the GFPimmunolabeled axon profile in $a$ is also tightly associated with an adjacent host astrocyte (As). Magnification 5000×.
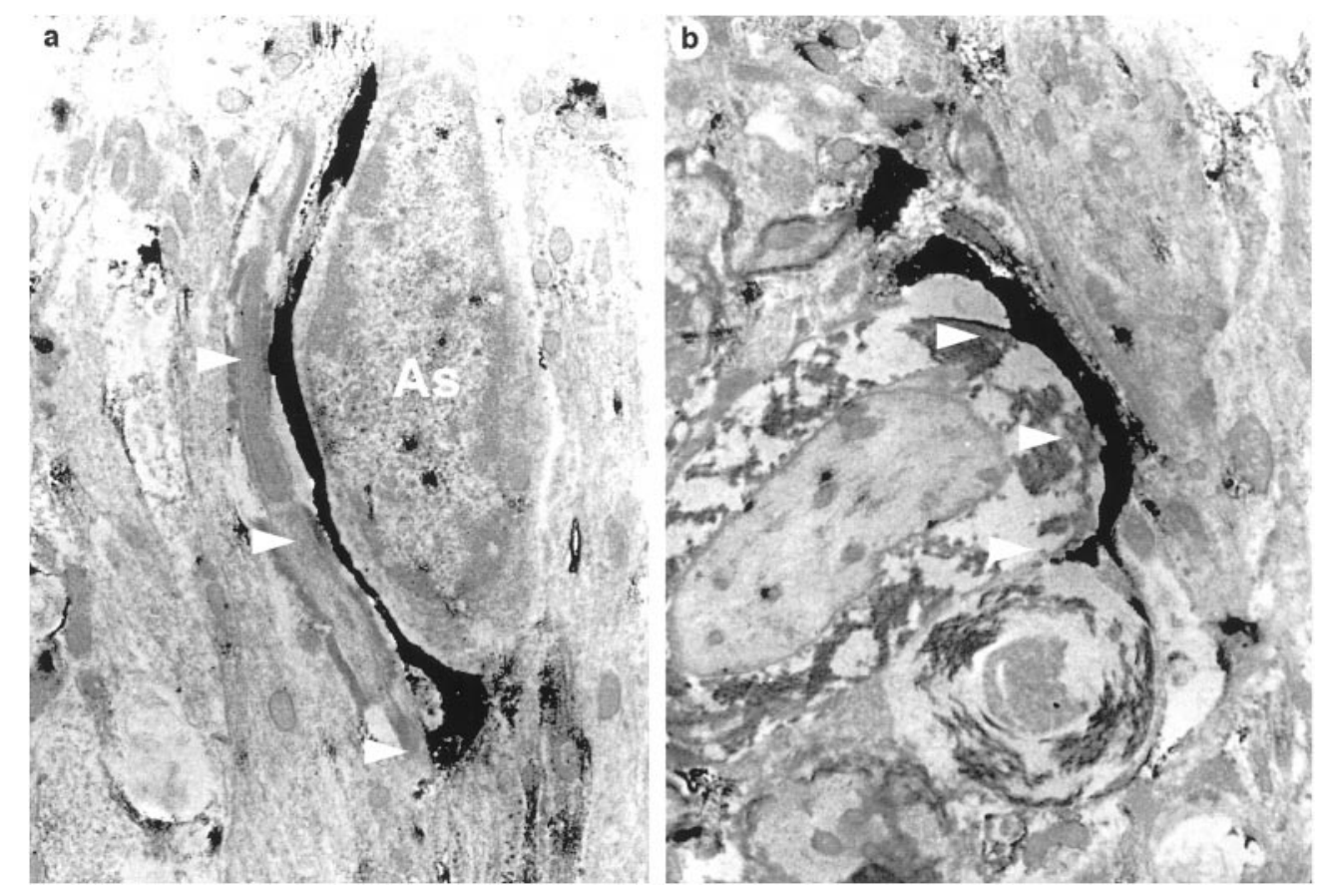

GFAP, and CSPGs revealed that the majority of axons had stopped at varying distances from the lesion center within reactive scar tissue, with their positions of arrested growth correlating with increased immunoreactivity for CSPGs and GFAP. Axon extension had, therefore, stopped correspondingly further from the lesion center within the greater rostral spread of dense scar tissue nearer the pial surface (Fig. 7a,b). A few axons had penetrated several hundred micrometers through the intensely GFAPimmunoreactive edges of the lesion site to within a few tens of micrometers of the lesion center. However, these were invariably in the more ventrally situated dorsal column white matter where these axons were presented with lesser extent of rostrally spread scar tissue (Fig. 7a,b).

\section{DISCUSSION}

Our present study was designed to evaluate the relative inhibitory contributions of white matter undergoing Wallerian degeneration distal to a site of a severe lesion versus glial scarring at the actual site of trauma in causing the failure of sensory axon regeneration within the adult spinal cord. To accomplish this we have used the microtransplantation technique to place grafts of adult sensory neurons into acutely and chronically degenerating spinal cord white matter several millimeters distal to a severe lesion without provoking the formation of a second glial scar at the transplantation site. We have demonstrated the robust and efficient regeneration of an unprecedented number of large- and small-diameter DRG axons not only within control, undamaged dorsal columns of the adult spinal cord but, even more surprisingly, in both acute as well as chronically degenerating white matter, so long as the donor neurons are introduced away from the primary lesion with minimal added trauma.

Growth cone shape is a sensitive barometer that can reflect the nature of the cell-to-cell interactions that may be occurring between an axon and its environment. Our experiments revealed that the overall rate of regeneration and growth cone morphology of adult axons from transplants in normal and degenerating white matter were equivalent, with axons exhibiting streamlined growth cones indicative of unimpeded outgrowth (Mason and Wang, 1997). At present we cannot account for the slowing of growth of rostrally directed axons on their arrival at the entrance to the brainstem dorsal column nuclei, although a similar phenomenon has been observed for embryonic callosal axons on nearing their targets (Halloran and Kalil, 1994). Because of our decision not to alter the spinal cord inflammatory reaction to injury with the use of cyclosporin immunosuppressant (Palladini et al., 1996), we were not able, in the present series of experiments, to study the longer term capacities of the donor axons to innervate the dorsal column nuclei. There was, however, clear evidence of substantial invasion and terminal arborization within the dorsal horn gray matter all along the route of regeneration. That the rectilinear growth of collaterals and some primary GFP+ axons within dorsal column white matter was invariably directed toward dorsal horn gray matter suggests positive guidance cues influencing appropriate terminal field invasion. This is in contrast to the lack of collateral formation observed for DRG axons within the callosum and fimbria where side branching into inappropriate gray matter of the cortex and hippocampus was not observed (Davies et al., 1997). Whether precise synaptic matching within the spinal cord had occurred between subtypes of primary neurons with secondary targets is presently under investigation.

Adult axons with streamlined growth cones were observed to have rapidly regenerated right up to the border of a massive injury, although the entire field of white matter glia distal to the area of injury was gliotic. This observation suggests that regenerating axons in not only the undamaged cord but also within the midst of fulminant Wallerian degeneration with its accompanying glial changes appear not to be in a struggle with an environment that must surely contain large compliments of purportedly potent myelin-associated inhibitors such as NOGO (Huber et al., 1998) and MAG in both its bound and soluble forms (Tang et al., 1997). Indeed, our immuno-EM analysis of regenerating axons within degenerating white matter showed regenerating axons in intimate contact with myelin as well as astroglia. Surprisingly, 

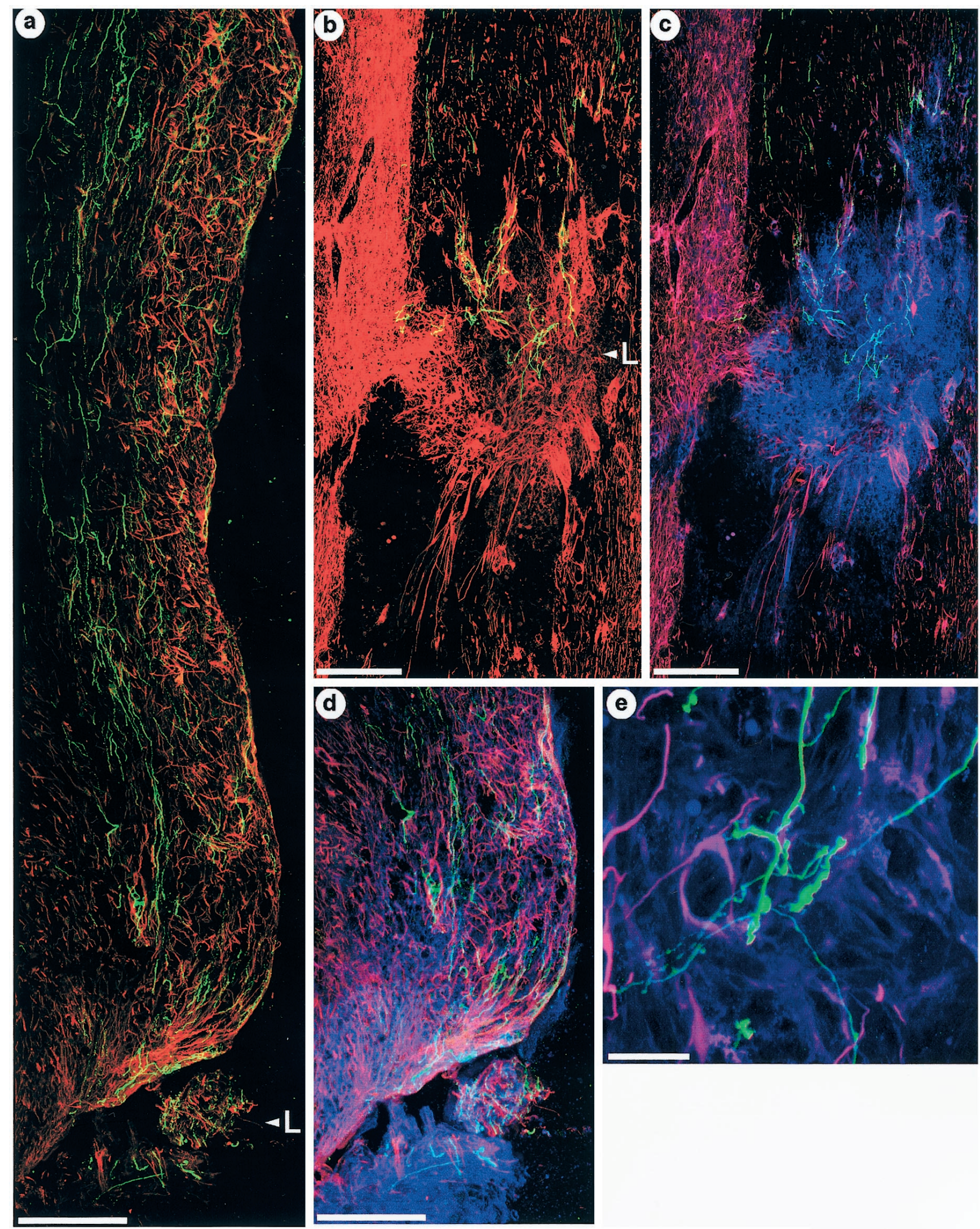

Figure 6. Failure of regeneration on reaching the glial scar. $a, b$, Double channel confocal images $(60 \mu \mathrm{m})$ from two $8 \mathrm{~d}$ survival set 2 cases showing numerous caudally regenerating GFP+ (green channel) adult sensory axons that have grown 4-5 mm through acutely degenerating and gliotic (GFAP, red channel) dorsal column white matter to eventually invade and stop within the lesion sites $(L$, arrowhead). $c, d$, Triple channel confocal images of the same lesion sites in $a$ and $b(a, d ; b, c)$ that are additionally stained for CSPGs (blue channel) and show that the failure of regeneration correlates with axons entering high levels of inhibitory proteoglycans found only within the lesion site. $e$, A high-power triple channel confocal scan (GFP, green; GFAP, red; CSPG, blue) showing that the growth cones of regenerating GFP+ axons have been transformed into dystrophic endings within the CSPG-rich, reactive astrocytic terrain of the lesion. Scale bars: $a, b, 200 \mu \mathrm{m} ; c, d, 250 \mu \mathrm{m} ; e, 25 \mu \mathrm{m}$. 

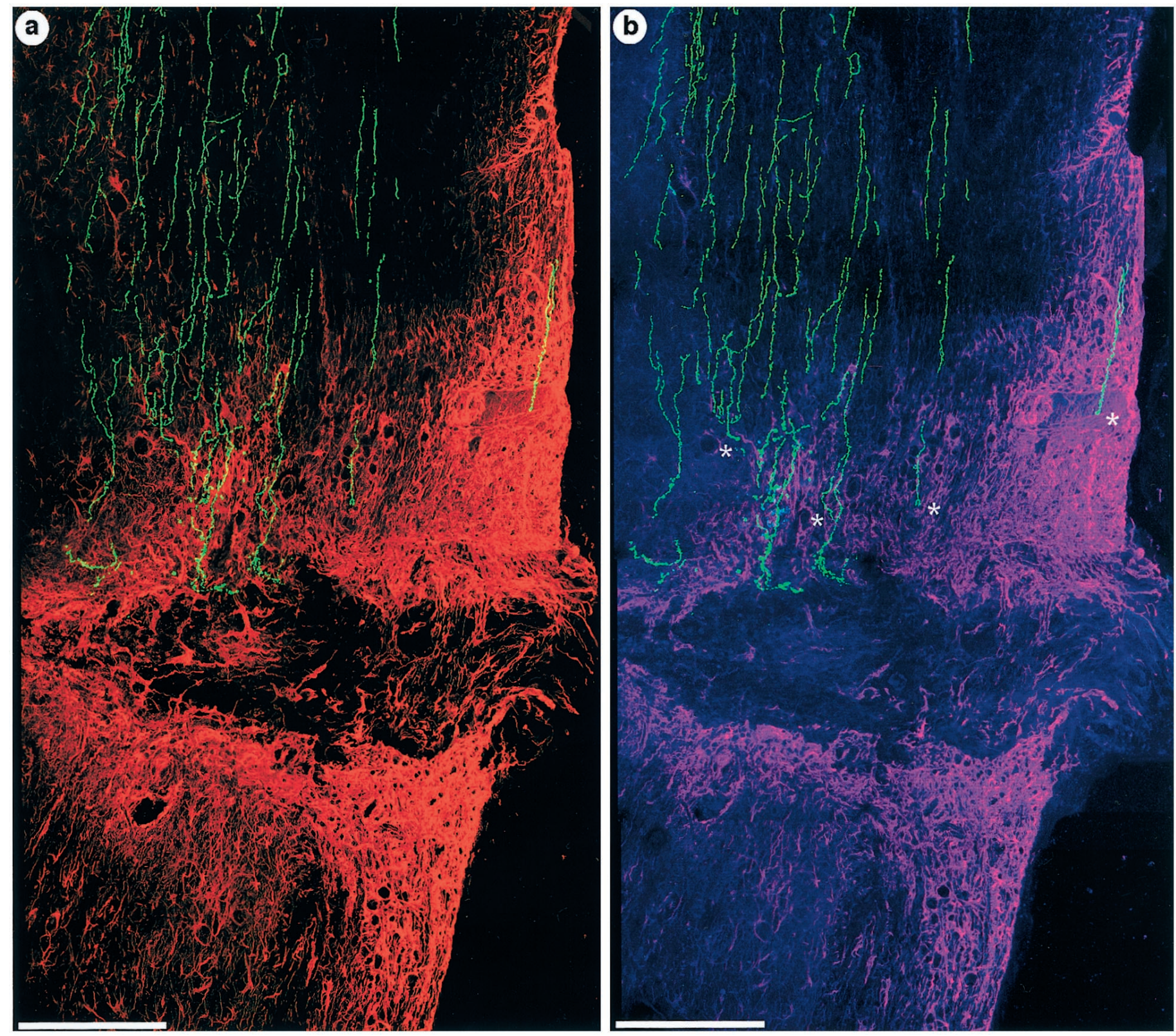

Figure 7. Axon regeneration in chronic degenerating white matter and its failure after reaching the glial scar. $a$, $b$, Double and triple channel confocal images, respectively (GFP, green channel; GFAP, red channel; CSPG, blue channel) through $60 \mu \mathrm{m}$ of a lesion site from 3 month chronic set 3 animal that has received an adult DRG neuron microtransplant rostral to the injury site. Numerous GFP+ axons have regenerated $4-5$ mm caudally from the site of transplantation through chronically degenerating dorsal column white matter. After reaching mature scar, the regenerating axon tips have stopped and taken on a dystrophic appearance at varying distances from the center of the lesion ( $b$, asterisks) within the CSPG (b, blue channel)-immunoreactive and intensely GFAP+-reactive gliotic scar tissue bordering the site of injury. Note the abrupt termination of regeneration at the center of the lesion site for the few more ventrally placed axons that were capable of traversing the correspondingly shorter rostral spread of reactive astroglia compared with that found nearer the pial surface. Survival $8 \mathrm{~d}$ after transplantation. Scale bars, $250 \mu \mathrm{m}$.

well away from the direct site of trauma and scar formation, alignment of astrocytic processes had been maintained within dorsal column white matter that had undergone Wallerian degeneration for up to 3 months ( $+8 \mathrm{~d}$ after transplantation survival).

The nature of the growth-promoting cues presented by degenerating white matter that lacks viable axons as well as containing overtly reactive glial cells and myelin debris are at present entirely unknown, although the alignment and close association of EGFP + axons with the processes of tract astrocytes suggests that they are playing a growth-supportive role. Interestingly, it has previously been shown that the apparent inhibitory effects of mature oligodendrocytes on neurite outgrowth in culture (Bandtlow et al., 1990; and verified by our own observations for adult rat and mouse DRG neurons) can be similarly overcome in the presence of astrocytes (Ard et al., 1991; Fawcett et al., 1992). The surface membranes of mature astrocytes as well as reactive astrocytes are capable of maintaining the elongation of neurites in vitro (Smith et al., 1990), and in vivo, adult reactive astrocytes have been demonstrated to upregulate production of laminin (Liesi et al., 1984) and neurotrophins in response to injury (Goss et al., 1998). Our present data lends strong support to the concept that not all forms of the astrocytic reactive state are equivalent 
(Mansour et al., 1990; Hoke and Silver, 1994), and that proximity to the immediate vicinity of a lesion determines whether the reactive glial environment will be growth-supportive or inhibitory. We were most excited to learn that even after relatively long periods ( 3 months), the distal tract still remained permissive for the regeneration of sensory axons, although there were indications that white matter nearer the pial surface within $3 \mathrm{~mm}$ of the lesion was becoming refractory to axon growth.

Importantly, the bidirectional growth of axons from the grafts allowed the unique opportunity of examining the behavioral changes of caudally directed growth cones after encountering the environment of forming as well as mature glial scar tissue, having already regenerated rapidly within degenerating CNS white matter. By far, the most striking change in rate of axon growth and morphogenetic transformation of growth cones occurred after reaching the inwardly directed gradient of increasingly CSPGrich ECM associated with the lesion. Here, their change from rapidly elongating, streamlined growth cones to bulbous dystrophic endings strongly correlated with the arrival of axons at the highest concentrations of CSPGs found nearer the lesion center. Therefore, most dystrophic axonal endings were not found at the very outer edges of the reactive site of injury but within the boundaries of the CSPG "cloud" where they had stopped forward growth at effectively half the distance normally covered from the site of implantation in both unlesioned and lesioned white matter. Indeed, in only two $8 \mathrm{~d}$ cases in the acute set 2 animals were a total of two axons observed to have had skirted around the perimeter of the lesion, essentially escaping the site of injury to emerge on the opposite side.

The tortuous and bulbous anatomy of the endings, described many times over by Ramon y Cajal (1928) in his studies of lesioned CNS pathways, was clearly reflective of the final hours or days in the life of a deteriorating growth cone as it enters the phase of long-term dystrophy. That such endings could develop so quickly on entering reactive glial matrix after a relatively long and rapid journey leads to the conclusion that cessation of axonal regrowth in the CNS must be under the strong inhibitory influence of molecular signals present within the environment of the lesion. The list of inhibitory scar-associated molecular candidates is rapidly growing with phosphacan, neurocan (McKeon and Buck, 1997), glial progenitor-expressed NG2 (Levine, 1994), and inhibitory membrane proteoglycan (Fernaud-Espinosa et al., 1998) being but several of the inhibitory proteoglycans alone that have so far been characterized at lesion sites. Other inhibitors expressed within adult CNS scar tissue include tenascin (Laywell et al., 1992) and semaphorin III, which has recently been shown to be associated with meningeal infiltrates that tend to reside at the center of stab lesions in which the arachnoid compartment is breached (Pasterkamp et al., 1998). Interestingly, the multiple branching behavior of donor axons after entering CSPG-rich scar tissue is similar to that described for the processes of neurons cultured on a substrate of phosphacan (Maeda and Noda, 1996) or with reactive astrocytes (Le Roux and Reh, 1996), suggesting the possibility that the adult GFP+ axons in the present study have been similarly signaled to acquire either dendritic or terminal arbor-like attributes within the white matter lesion site. It is also possible that physical constraints are a significant part of the inhibitory machinery of the scar. However, to snare the growth cone from all sides, mechanical effects are likely to be coincident with the rising levels of inhibitory ECM that increase toward the center of the lesion, which appears to be especially impenetrable in mature scar tissue generated via a stab injury.
What enables growth cones to enter and grow within the lesion epicenter albeit for only short and variable distances? A partial answer to this question comes from tissue culture studies that have shown (1) that functionally inhibitory reactive astroglial cells simultaneously offer both inhibitory ECM and stimulatory membrane cues to axons (Canning et al., 1996) and (2) that sensory axons can, within limits, upregulate specific integrin receptors, enabling them to more efficiently use growthpromoting laminin presented within an experimentally contrived two-dimensional step gradient of a mixture of laminin and increasing aggrecan (Snow and Letourneau, 1992; Condic and Letourneau, 1997). Whether adult regenerating growth cones have this same capacity for rapid receptor malleability in vivo is unknown. Conceivably, within the greater constraints presented by the three-dimensional inhibitory matrix found in scar tissue, a lack of receptor plasticity in the adult neuron could be a significant factor in the conversion of the axonal cytoskeleton into a steady state of senescence.

What are the cellular and molecular mechanisms that cause the abrupt halt of the few axons that reached the center of a stab lesion, especially in the mature scar? This may be effected by the progressive development of an increasingly inhibitory environment at the center of a stab lesion, primarily caused by a fibroblastic invasion (Krikorian et al., 1981), coupled with a relative lack of astrocytes and consequent downward shift in the balance of reactive astroglial growth-promoting molecules. Such a sudden change in repulsive substrate characteristics may offer the already struggling growth cone an altered environment to which it cannot adapt.

In conclusion, we believe that our observations constitute compelling evidence that the glial scar and, hence, inhibitory factors such as proteoglycans at this locale, constitute the major environmental impediment to regeneration in the adult CNS. Furthermore, our data show that normal as well as lesioned distal white matter well away from an area of trauma is robustly permissive for long axon regrowth, at least for adult sensory axons emerging from the cell body. It is important that we acquire an understanding of the deleterious molecular or mechanical interactions that occur between growth cones and the reactive environment within adult CNS lesions to develop more effective bridging strategies that allow adult axons to use the massive potential for regeneration that the present study has shown exists beyond the glial scar.

\section{REFERENCES}

Amat JA, Ishiguro H, Nakamura K, Norton WT (1996) Phenotypic diversity and kinetics of proliferating microglia and astrocytes following cortical stab wounds. Glia 16:368-382.

Ard MD, Bunge MB, Wood PM, Schachner M, Bunge RP (1991) Retinal neurite growth on astrocytes is not modified by extracellular matrix, anti-L1 antibody, or oligodendrocytes. Glia 4:70-82.

Bandtlow C, Zachleder T, Schwab ME (1990) Oligodendrocytes arrest neurite growth by contact inhibition. J Neurosci 10:3837-3848.

Berry M, Maxwell WL, Logan A, Mathewson A, McConnell P, Ashhurst DE, Thomas GH (1983) Deposition of scar tissue in the central nervous system. Acta Neurochir Suppl (Wien) 32:31-53.

Bruck W (1997) The role of macrophages in Wallerian degeneration. Brain Pathol 7:741-52.

Cal D, Shen Y, De Bellard ME, Tang S, Filbin MT (1999) Prior exposure to neurotrophins blocks inhibition of axonal regeneration by MAG and myelin via a cAMP-dependent mechanism. Neuron 22:89-101.

Canning DR, Hoke A, Malemud C, Silver J (1996) A potent inhibitor of neurite outgrowth that predominates in the extracellular matrix of reactive astrocytes. ISDN 14:153-175.

Condic ML, Letourneau PC (1997) Ligand-induced changes in integrin expression regulate neuronal adhesion and neurite outgrowth. Nature 389:852-856. 
David S, Aguayo AJ (1981) Axonal elongation into peripheral nervous system "bridges" after central nervous system injury in adult rats. Science 214:931-933.

Davies SJA, Field PM, Raisman G (1993) Long fibre growth by axons of embryonic mouse hippocampal neurons microtransplanted into the adult rat fimbria. Eur J Neurosci 5:95-106.

Davies SJA, Field PM, Raisman G (1994) Long interfascicular axon growth from embryonic neurons transplanted into adult myelinated tracts. J Neurosci 14:1596-1612.

Davies SJA, Field PM, Raisman G (1996) Regeneration of cut adult axons fails even in the presence of continuous aligned glial pathways. Exp Neurol 142:203-216.

Davies SJA, Fitch MT, Memberg SP, Hall AK, Raisman G, Silver J (1997) Regeneration of adult axons in white matter tracts of the central nervous system. Nature 390:680-683.

DiProspero NA, Meiners S, Geller HM (1997) Inflammatory cytokines interact to modulate extracellular matrix and astrocytic support of neurite outgrowth. Exp Neurol 148:628-639.

Emmett CJ, Jaques-Berg W, Seeley PJ (1989) Microtransplantation of neural cells into adult brain. Neuroscience 38:213-222.

Fawcett JW, Fersht N, Housden L, Schachner M, Pesheva P (1992) Axonal growth on astrocytes is not inhibited by oligodendrocytes. J Cell Science 103:571-579.

Fernaud-Espinosa I, Nieto-Sampedro M, Bovolenta P (1998) A neurite outgrowth-inhibitory proteoglycan expressed during development is similar to that isolated from adult brain after isomorphic injury. J Neurobiol 36:16-29.

Fields DR, Schwab M, Silver J (1999) Does CNS myelin inhibit axon regeneration? The Neuroscientist 5:12-18.

Franson P, Ronnevi L-O (1984) Myelin breakdown and elimination in the posterior funiculus of the adult cat after dorsal rhizotomy: a light and electron microscopic qualitative and quantitative study. J Comp Neurol 223:138-151.

Gehrmann J, Matsumoto Y, Kreutzberg GW (1995) Microglia: intrinsic immunoeffector cell of the brain. Brain Res Rev 20:269-287.

George R, Griffin JW (1994) The proximo-distal spread of axonal degeneration in the dorsal columns of the rat. J Neurocytol 23:657-667.

Giulian D, Li J, Li X, George J, Rutecki PA (1994) The impact of microglia-derived cytokines upon gliosis in the CNS. Dev Neurosci 16:128-136.

Goss JR, O'Malley ME, Zou L, Styren SD, Kochanek PM, DeKosky ST (1998) Astrocytes are the major source of nerve growth factor upregulation following traumatic brain injury in the rat. Exp Neurol 149:301-309.

Halloran MC, Kalil K (1994) Dynamic behaviors of growth cones extending in the corpus callosum of living cortical brain slices observed with video microscopy. J Neurosci 14:2161-2177.

Hoke A, Silver J (1994) Heterogeneity among astrocytes in reactive gliosis. Perspect Dev Neurobiol 2:269-274.

Hoke A, Silver J (1996) Proteoglycans and other repulsive molecules in glial boundaries during development and regeneration of the nervous system. Prog Brain Res 108:149-163.

Huber AB, Chen MS, van der Haar ME, Schwab ME (1998) Developmental expression pattern and functional analysis of NOGO (formerly NI-35/250), a major inhibitor of CNS regeneration. Soc Neurosci Abstr 24:616.6.

Koshinaga M, Whittemore SR (1995) The temporal and spatial activation of microglia in fiber tracts undergoing anterograde and retrograde degeneration following spinal cord lesion. J Neurotrauma 12:209-222.

Krikorian JG, Guth L, Donati EJ (1981) Origin of the connective tissue in the transected rat spinal cord. Exp Neurol 72:698-707.

Lander AD (1993) Proteoglycans in the nervous system. Curr Opin Neurobiol 3:716-723.

Laywell ED, Dorries U, Bartsch U, Faissner A, Schachner M, Steindler DA (1992) Enhanced expression of the developmentally regulated extracellular matrix molecule tenascin following adult brain injury. Proc Natl Acad Sci USA 89:2634-2638.

Le Roux PD, Reh TA (1996) Reactive astroglia support primary dendritic but not axonal outgrowth from mouse cortical neurons in vitro. Exp Neurol 137:49-65.
Levine JM (1994) Increased expression of the NG2 chondroitin-sulfate proteoglycan after brain injury. J Neurosci 14:4716-4730.

Liesi P, Kaakkola S, Dahl D, Vaheri A (1984) Laminin is induced in astrocytes of the adult brain by injury. EMBO J 3:683-686.

Liu XZ, Xu XM, Hu R, Du C, Zhang SX, McDonald JW, Dong HX, Wu YJ, Fan GS, Jacquin MF, Hsu CY, Choi DW (1997) Neuronal and glial apoptosis after traumatic spinal cord injury. J Neurosci 17:5395-5406.

Maeda N, Noda M, (1996) 6B4 proteoglycan/phosphacan is a repulsive substratum but promotes morphological differentiation of cortical neurons. Development 122:647-658.

Mansour H, Asher R, Dahl D, Labkovsky B, Perides G, Bignami A (1990) Permissive and non-permissive reactive astrocytes: immunofluorescence study with antibodies to the glial hyaluronate-binding protein. J Neurosci Res 25:300-311.

Mason CA, Wang LC (1997) Growth cone form is behavior-specific and, consequently, position-specific along the retinal axon pathway. J Neurosci 17:1086-1100.

Margolis RK, Margolis RU (1993) Nervous tissue proteoglycans. Experimentia 49:429-446.

McKeon RJ, Buck CR (1997) Gene expression in glial scars following CNS injury. Soc Neurosci Abstr 23:777.1.

McKeon RJ, Schreiber RC, Rudge JS, Silver J (1994) Reduction of neurite outgrowth in a model of glial scarring following CNS injury is correlated with the expression of inhibitory molecules on reactive astrocytes. J Neurosci 11:3398-3411.

McKerracher L, David S, Jackson DL, Kottis V, Dunn RJ, Braun PE (1994) Identification of myelin associated glycoprotein as a major myelin-derived inhibitor of neurite growth. Neuron 13:805-811.

Murray M, Wang SD, Goldberger ME, Levitt P (1990) Modification of astrocytes in the spinal cord following dorsal root or peripheral nerve lesions. Exp Neurol 110:248-257.

Okabe M, Ikawa M, Kominami K, Nakanishi T, Nishimune Y (1997) "Green mice" as a source of ubiquitous green cells. FEBS Lett 407:313-319.

Palladini G, Caronti B, Pozzessere G, Teichner A, Buttarelli FR, Morselli E, Valle E, Venturini G, Fortuna A, Pontieri FE (1996) Treatment with cyclosporin A promotes axonal regeneration in rats submitted to transverse section of the spinal cord: recovery of function. J fur Hirnforschung 37:145-153.

Pasterkamp RJ, De Winter F, Holtmaat AJGD, Verhaagen J (1998) Evidence for a role of the chemorepellant semaphorin III and its receptor neuropillin-1 in the regeneration of primary olfactory axons. J Neurosci 18:9962-9976.

Ramon y Cajal S (1928) Degeneration and regeneration of the nervous system. London: Oxford UP.

Schwab ME, Kapf hammer JP, Bandtlow CE (1993) Inhibitors of neurite growth. Annu Rev Neurosci 16:565-595.

Skoff RP (1975) The fine structure of pulse labeled (3H-thymidine cells) in degenerating rat optic nerve. J Comp Neurol 161:595-611.

Smith GM, Rutishauser J, Silver J, Miller RH (1990) Maturation of astrocytes in vitro alters the extent and molecular basis of neurite outgrowth. Dev Biol 138:377-390.

Snow DM, Letourneau PC (1992) Neurite outgrowth in a step gradient of chondroitin sulfate proteoglycan. J Neurobiol 23:322-336.

Snow DM, Steindler DA, Silver J (1990) Molecular and cellular characterization of the glial roof plate of the spinal cord and optic tectum: a possible role for a proteoglycan in the development of an axon barrier. Dev Biol 138:359-376.

Tang S, Woodhall RW, Shen YJ, deBellard ME, Saffell JL, Doherty P, Walsh FS, Filbin MT (1997) Soluble myelin-associated glycoprotein (MAG) found in vivo inhibits axonal regeneration. Mol Cell Neurosci 9:333-346.

Vestergaard S, Tandrup T, Jakobsen J (1997) Effect of permanent axotomy on number and volume of dorsal root ganglion cell bodies. J Comp Neurol 388:307-312.

Windle WF, Clemente CD, Chambers WW (1952) Inhibition of formation of a glial barrier as a means of permitting a peripheral nerve to grow into the brain. J Comp Neurol 96:359-369. 